\title{
Reconceptualising fair access to highly academically selective universities
}

\author{
Vikki Boliver $^{1} \cdot$ Pallavi Banerjee ${ }^{2} \cdot$ Stephen Gorard $^{3} \cdot$ Mandy Powell $^{4}$
}

Accepted: 18 August 2021 / Published online: 6 September 2021

(C) The Author(s) 2021

\begin{abstract}
The higher education regulator for England has set challenging new widening access targets requiring universities to rethink how merit is judged in admissions. Universities are being encouraged to move away from the traditional meritocratic equality of opportunity model of fair access, which holds that university places should go to the most highly qualified candidates irrespective of social background, in accordance with the principles of procedural fairness. Instead, they are being asked to move towards what we term the meritocratic equity of opportunity model, which holds that prospective students' qualifications should be judged in light of the socioeconomic circumstances in which these were obtained to enhance distributive fairness, a practice known in the UK as contextualised admissions. In this paper, we critically discuss the theoretical underpinnings of these two competing perspectives on fair access and review the existing empirical evidence base, drawing together for the first time insights from our ESRC and Nuffield Foundation funded studies of fair access to highly academically selective universities in England. We argue that reconceptualising fair access in terms of distributive fairness rather than procedural fairness offers a more socially just set of principles on which to allocate valuable but scarce places at the most academically selective universities in England, unless or until such time as the vertical stratification of higher education institutions is reduced or eliminated entirely.
\end{abstract}

Keywords Equality $\cdot$ Equity $\cdot$ Procedural fairness $\cdot$ Distributive fairness $\cdot$ Higher education · Meritocracy $\cdot$ Contextualised admissions

\section{Introduction}

High participation systems of higher education are commonly characterised by a bifurcation between highly prestigious 'elite' universities - such as the Russell Group in the UK, the Ivy League in the USA, and the C9 universities in China — and low prestige 'demand absorbing'

Vikki Boliver

vikki.boliver@durham.ac.uk

Extended author information available on the last page of the article 
institutions attended by the majority of tertiary level students (Cantwell \& Marginson, 2018). Entry to the most prestigious universities within these systems is highly competitive, and prospective students are selected on the basis of their academic attainment in national examinations taken at age 18, such as A-levels in England and the Bachillerato in Spain, bespoke university entry tests, including the Gaokao in China and SAT and ACT in the USA, or based on earlier selection into different school tracks as in Belgium, Italy, and Poland, or some combination of the above (Haj et al., 2018). What all of these systems have in common is that they invariably lead to socially and economically stratified bodies of higher education students, especially within the elite tier of institutions, prompting critiques of the assumption that such stratification reflects the natural outcome of 'fair' merit-based testing and selection (Marginson, 2018).

In England, the primary focus of this paper, the traditional consensus - that meritocratic selection based on academic attainment is inherently just - is being challenged by new national widening access policies focused on achieving greater social equity in admissions. Following two decades of slow progress towards closing the socioeconomic gap in rates of access to the most academically selective universities (Boliver, 2015), the higher education regulator for England, the Office for Students (OfS), recently called on the most academically selective universities to equalise the ratio of entrants from areas of the country with high and low rates of participation in higher education, from a baseline of $5: 1$ in 2017 to $3: 1$ by 2025 and to $1: 1$ by 2039 (OfS, 2018). ${ }^{1}$ Highly selective universities run the risk of losing funding if they do not demonstrate steady progress towards more diverse student intakes.

In order to meet these ambitious new widening access targets, the higher education regulator has encouraged the most academically selective universities to engage in a process of 'rethinking how merit is judged in admissions' (OfS, 2019: 8). The call to 'rethink merit' is built on the idea that the single biggest obstacle to widening access to highly academically selective universities is the impact of socioeconomic inequality on prior academic attainment, a concern shared by critics of other highly selective admission systems including that of China (Liu, 2013; Liu \& Helwig, 2020) and the USA (McNamee \& Miller Jr., 2004). More concretely, highly academically selective universities in England have been asked to be bolder in their use of contextualised approaches to admissions which take into account the socioeconomic circumstances in which applicants' qualifications were achieved and, at the more ambitious end, involve significantly reducing academic entry requirements for applicants from socioeconomically disadvantaged backgrounds. This emphasis on contextualising admissions parallels the recent introduction of minimum entry requirements for socioeconomically disadvantaged applicants to universities in Scotland (CoWA, 2016), the 'holistic assessment' of applicant merit in some US states such as California (Liu, 2011), and the use of affirmative action policies in the US and around the world to help equalise higher education access rates for members of disadvantaged ethnic minority groups (Warikoo \& Allen, 2020).

Drawing on insights from our recently competed ESRC and Nuffield Foundation funded studies, this paper presents a theoretical and empirical critique of the traditional meritocratic equality of opportunity paradigm that has underpinned the conventionally high bar set for

\footnotetext{
${ }^{1}$ While we do not dwell on this point in this paper, it is important to note that geographic measures, including the POLAR measure used by the OfS which divides areas into quintiles based on young people's higher education participation rates, are a poor proxy for the socioeconomic circumstances of individuals and so have a high risk of mis-identifying the intended beneficiaries of widening access initiatives. Elsewhere we have called for geographic measures to be abandoned in favour of individual-level metrics, such as eligibility for free school meals as an indicator of low household income (Boliver et al., 2021; Gorard et al., 2019).
} 
admission to the most academically selective universities. This model holds that, for reasons of both efficiency and social justice, university places should go to the candidates with the highest qualifications irrespective of their social background, in accordance with the principle of procedural fairness. Our review of the evidence shows that this model fails on its own terms, with 'merit' as indexed by prior attainment shown to be just one of several determinants of access to selective universities in England. More importantly, we show that the model rests on the untenable assumption of equality of opportunity, regardless of socioeconomic circumstances, to demonstrate 'merit' via formal examinations taken at the end of compulsory schooling.

In place of the traditional meritocratic equality of opportunity model, we argue in favour of an alternative meritocratic equity of opportunity model of fair access to highly selective universities. Rooted in the theoretical ideas of Rawls (1971, 2001a) and Sen (1979, 2009), the meritocratic equity of opportunity model recognises that the prior attainment of those from disadvantaged backgrounds does not necessarily do justice to their ability and potential. This alternative model does not do away with the notion of merit, but calls for prospective students' university qualifications to be judged in light of the socioeconomic circumstances in which they were obtained and for disadvantaged students to be supported to achieve their potential once enrolled at university. Instead of emphasising the need for procedural fairness interpreted as equal treatment, the meritocratic equity of opportunity models calls for individuals to be treated differently depending on their social background in the pursuit of a greater degree of distributive fairness with respect to the allocation of university places.

\section{The meritocratic equality of opportunity model of fair access}

Although the ideas date back to Kong Qiu and probably beyond, the traditional meritocratic equality of opportunity model of fair access to higher education has its roots in theories of meritocracy developed in the mid-twentieth century by sociologists seeking to theorise the development of modern industrialised societies (Bell, 1973; Parsons, 1970; Treiman, 1970). The concept of meritocracy refers to a system for allocating occupational and social roles based on the supposedly objective assessment of the abilities and achievements of individuals instead of ascribed characteristics such as inherited social class background (aristocracy), or gender and ethnicity. Literally denoting a society governed ('ocracy') by those who have earned it ('merit'), the theory of meritocracy holds that the increasingly specialised and skilled nature of occupational roles in highly developed societies requires that occupations be filled by the most capable individuals irrespective of social background. National education systems involving universal access to primary and secondary education and an expanded higher education sector are seen as playing an increasingly important role in the functioning of a meritocratic society. They supposedly provide equality of opportunity for all to develop competences that are key to effective occupational performance and equal opportunity for all to have these competencies certified through objective methods of assessment based on universal rather than particular standards (Parsons, 1970).

Meritocratic societies could be considered to be more efficient than previous forms of social organisation in which positions had tended to be passed down from one generation of family members to the next, or through closed networks, because allocating occupational and social positions to the most competent individuals regardless of social origin should maximise both the average and the total utility of individuals in society. Meritocratic societies are also generally seen to be more socially just. Because the success of individuals in education and 
the labour market is determined by individual achievement rather than social ascription, unequal outcomes in a meritocratic society, including inequalities in economic rewards and social esteem, are deemed to be legitimate because they are deserved.

Meritocracy was not expected nor intended to eliminate socioeconomic inequalities and social hierarchies, but rather to provide 'equal opportunity to be unequal' (Norman, 1987: 68) via 'the displacement of one principle of stratification by another, of achievement for ascription' (Bell, 1973: 426). However, meritocracy was expected to substantially weaken the intergenerational link between socioeconomic origins and destinations, with meritocratic societies anticipated to display high rates of intergenerational social mobility due to a reduced influence of social origins on educational attainment and an increased impact of educational attainment on subsequent occupational attainment (Treiman, 1970).

Indeed, the purported shift from ascription to achievement as the basis for allocating occupational and social roles was heralded by meritocracy theorists as a progressive development, part of a wider trend towards greater democratisation of access to educational opportunities and subsequently to positions of power, privilege, and prestige. Within higher education, the historic principle of restricting access to those displaying 'inherited merit' by virtue of their social origin was being replaced by the principle of 'equality of opportunity' to compete for a place at university on the basis of individual merit (Goastellec, 2008).

The meritocratic equality of opportunity paradigm gives primacy to procedural fairness interpreted as requiring all to be judged according to the same criteria and processes so that all have equal opportunity to demonstrate merit. In the case of admission to higher education, the operation of procedural fairness entails evaluating all applicants to a given course at a given institution against the same set of academic entry requirements, regardless of social background and other characteristics which are judged as merit-irrelevant. This has been characterised as a shift away from an 'organic conservatism' which historically 'defended social privilege and supported explicit class bias in admissions' towards a form of 'democratic elitism' involving admission on the basis of 'the "amoral elite" criteria of academic excellence' (Nahai, 2013: 6).

\section{Evaluating the meritocratic equality of opportunity model}

A significant body of empirical research has explored whether access and admission to UK universities can be said to be fair in the traditional meritocratic equality of opportunity sense that there is no residual impact of social background after merit in the form of prior attainment has been taken into account. Typically, these studies have found that access and admissions to UK universities are substantial but by no means wholly fair in the traditional meritocratic sense.

An analysis of linked NPD and HESA data found that public examination results achieved at ages $11,14,16$, and 18 accounted for $62 \%$ of the 31.2 percentage point raw difference between low-SES and high-SES young men in their probabilities of attending a high status university given participation in HE at all (Chowdry et al., 2013). A further 30\% of the raw gap was accounted for by combination of individual characteristics - specifically ethnicity, English as an additional language, special educational needs, and month of birth - and by school fixed effects that capture the impact of the specific school attended. The findings were broadly similar for males and females. The authors of the study conclude that socioeconomic inequalities of access to higher education occur 'largely because lower SES pupils do not achieve as highly in secondary school as their more advantaged counterparts' (p. 454). While this is indeed the case, what is also clear from their findings is that access inequalities are not fully linked to prior attainment and so 
may be non-meritocratic to some extent as well. Similar findings have emerged from studies of those educated in state-funded as opposed to private fee-paying schools (Sullivan et al., 2014), those who are among the first generation of family members to go to university (Adamecz-Völgyi et al., 2020), and those from lower income households (Anders, 2012), as well as care leavers and FSM-eligible students (Harrison, 2019). All of these have been shown to be somewhat less likely than their more advantaged peers to participate in the most selective universities, even after controlling statistically for prior attainment.

Other studies have examined socioeconomic differences in propensities to apply to more academically selective universities. Analysis of data for the period 1996-2006 provided by the Universities and Colleges Admissions Service (UCAS) - the organisation that processes almost all applications to full-time undergraduate programmes in the UK-found that university applicants from lower social class backgrounds and from non-selective state schools were less likely to apply to the more selective Russell Group universities than their comparably qualified counterparts from higher social class backgrounds and private schools (Boliver, 2013). A replication of this analysis for the period 2010-2011 to 2012-2013 found similar results for those from non-selective state schools and from geographic areas with HE participation rates in the lowest quintile of the distribution nationally (Boliver, 2016). These findings chime with those of a study which showed that university entrants from lower socioeconomic backgrounds were more likely than peers from higher socioeconomic backgrounds to hold qualifications that exceeded the entry requirements for their chosen course (Campbell et al., 2019; Wyness, 2017). The authors refer to this as being 'under-matched' and argue that this implies that socioeconomically disadvantaged students are less well-represented at the most academically selective universities than their academic attainments would warrant.

A further set of studies have drawn on Universities and Colleges Admissions Service data to explore the determinants of being offered a place at university conditional on application. This body of work has invariably found that while previous academic attainment is the strongest predictor of admission, admissions chances differ for applicants from different social groups even when they hold the same grades and have studied the same subjects at A-level. These studies have shown that the chances of comparably qualified applicants being admitted to more academically selective universities are lower for those from non-selective state maintained as compared to private fee-paying schools (Boliver, 2013; Noden et al., 2014), from lower as compared to higher social class backgrounds (Zimdars et al., 2009), and from areas with low as compared to high rates of HE participation (Boliver, 2016). Studies looking at particular degree subjects such as Medicine and Law have yielded similar results (Dilnot \& Boliver, 2018; Houston et al., 2015).

It is not clear why access and admissions appear to be less clearly linked to prior attainment than is often claimed, but one likely factor is that most university application choices and admissions decisions are made on the basis of applicants' predicted A-level grades before actual attainment at A-level is known. Research has shown that only $16 \%$ of applicants have their grades predicted accurately, whereas grades are under-predicted for $9 \%$ of applicants and overpredicted for a considerable 75\% (Wyness, 2016). Another study found that only around half of all individual grade predictions were accurate, with $41 \%$ being over-predictions and $6.6 \%$ being under-predictions (Everett \& Papageorgiou, 2011). Those from comparatively disadvantaged backgrounds - state schools, lower social class backgrounds, low HE participation areas, and the Black and Asian ethnic groups - are most likely to have their grades over-predicted, generally speaking (Wyness, 2016). However, among higher-performing students in particular, low-SES students are more likely to have their grades under-predicted relative to their more 
advantaged peers (Campbell et al., 2019; Wyness, 2017). These findings have prompted calls for a post-qualifications admissions system (PQA) in which all university applications and admissions decisions are made after applicants have received their A-level and equivalent examination results (Atherton \& Nartey, 2019; Holt-White et al., 2020).

The studies discussed so far indicate that patterns of application and admission to highly academically selective UK universities are substantially, but by no means wholly, meritocratic in the traditional sense. While prior qualifications are the largest single determinant of the likelihood of application and of admission to these universities, large socioeconomic disparities remain after differences in 'merit' have been taken into account.

\section{Theoretical critiques of the meritocratic equality of opportunity model}

Irrespective of whether or not prior attainment is the sole or overwhelming determinant of access to the UK's most academically selective universities, a more fundamental criticism of the traditional meritocratic model is that it rests on the false premise that there has been prior equality of opportunity to achieve the requisite academic qualifications. Bourdieu, writing in the 1970s, argued that the grading and certifying functions of meritocratic education institutions actually stratify individuals by rewarding qualities and capabilities such as familiarity with high culture that the education system itself does not cultivate but which the already advantaged disproportionately possess (Bourdieu, 1977). Through the apparently objective assessment of individual merit, the determining influence of pre-existing social inequalities on the educational outcomes of individuals is obscured by being rendered legitimate (Brown et al., 2016); as Bourdieu puts it: 'a social gift [is] treated as a natural one' (Bourdieu, 1974: 32). This naturalisation of educational outcomes, if it occurs, not only places working class students towards the bottom of the attainment distribution, but also inculcates in them the sense that they are wholly individually responsible for their success or failure (Reay, 2020).

Meritocracy theorists of the 1970s themselves occasionally acknowledged the tendency of societies organised according to the principles of meritocratic equality of opportunity to exacerbate socioeconomic inequality and foster elite social reproduction. As US sociologist and key advocate of meritocracy, Daniel Bell noted: 'There can never be a pure meritocracy because, invariably, high-status parents will seek to pass on their positions either through the use of influence or simply by the cultural advantages their children would possess. Thus, after one generation a meritocracy simply becomes an enclaved class' (Bell, 1973: 427). Bell's observation echoes that of sociologist Michael Young who has been credited with coining the term meritocracy in the late 1950s. Writing at a time when IQ tests were being used to assess the suitability of children for different kinds of secondary schooling in the UK, Young envisaged a dystopian future in which IQ tests had become the sole determinant of access to educational and occupational opportunities, resulting in a largely socially immobile society due to the intergenerational transmission within families not only of genetically inherited ability but also of the economic and cultural resources needed to nurture that ability (Young, 1958).

These caveats are supported by evidence which shows that socioeconomic inequalities may hamper the academic progress of disadvantaged pupils such that their grades in important school-leaving examinations can more often fail to do justice to their ability and potential. A study of the attainment trajectories of school pupils in England found that while pupils from socioeconomically advantaged backgrounds who were high achievers at age 7 continued to be higher achievers throughout their schooling careers, high achieving 7-year-olds from 
socioeconomically disadvantaged backgrounds fell steadily down the attainment distribution over time (Crawford et al., 2017). By age 16, socioeconomically disadvantaged pupils who had been high achievers at age 7 had in fact been overtaken by their more advantaged peers whose attainment had been merely average at age 7 . National statistics show that low-income young people eligible for free school meals in England have much lower average attainment at age 16 than non-FSM-eligible pupils, are around half as likely to continue to upper secondary education, and are only one-third as likely to have achieved qualifications equivalent to three A-levels at grades ABB or better by age 19, which would permit entry to at least some selective universities (Gorard et al., 2017). As such, young people from socioeconomically disadvantaged backgrounds are much less likely than their more advantaged peers to meet the high academic entry requirements set by the most academically selective universities regardless of their ability or potential.

That these divergent academic trajectories stem from socioeconomic inequalities in wider society is well supported by the sociological literature. Young people from less advantaged backgrounds are, by definition, less likely to benefit from material circumstances at home that are more conducive to intellectual development and academic success or be able to draw support for their learning from educationally successful family members (Wikeley et al., 2008). Disadvantaged young people are also less likely to access better resourced fee-paying private schools (Anders et al., 2020), and within the state-funded school sector, disadvantaged pupils tend to be disproportionately clustered in particular schools (Gorard \& Siddiqui, 2019), with lower average attainment and fewer peers planning applications to selective universities.

Importantly, an education system organised along traditional meritocratic lines is not only often inequitable but also inherently wasteful since ' $[\mathrm{u}]$ nrealised talent is therefore both the necessary and structural condition of its existence' (Littler, 2018: 3). Research published by the OECD confirms this wastefulness, showing that countries which sort pupils on the basis of academic performance into different secondary educational tracks display wider socioeconomic inequalities in attainment, but not higher average levels of educational performance overall (OECD, 2013). Moreover, the emerging consensus is that economic growth is slower, not faster, in more socioeconomically unequal societies (Cingano, 2014).

\section{Reconceptualising fairness as meritocratic equity of opportunity}

Two of the most influential challenges to the meritocratic equality of opportunity paradigm are the theory of justice as fairness advanced by the US philosopher John Rawls (Rawls, 1971, 2001b) and the capabilities approach developed by Indian philosopher Amartya Sen (1979 \& 2009). While the work of Rawls and Sen differ in several key respects, ${ }^{2}$ both theorists advocate for a conception of fairness as requiring equity, rather than ostensible equality, of opportunity.

\footnotetext{
${ }^{2}$ Sen describes his work as having developed out of an 'at once deeply appreciative and seriously critical' engagement with Rawls' ideas (Sen, 2009: 58). His critique of Rawls includes a dismissal of Rawls's contention that it is possible to reach a consensus on what constitutes fairness and that, if such a consensus were possible people, could be expected to abide by it in practice. Sen is also critical of Rawls' narrow focus on fairness as evidenced by the distribution of primary goods (e.g. civil and political rights, liberties, income, wealth, social esteem, and self-respect) which neglects to consider the personal, social, and environmental factors that affect a person's opportunities to convert these into real opportunities. Although such disagreements are important, we focus here on their central point of agreement on the need for genuinely equitable opportunity rather than mere formal equality of opportunity.
} 
Rawls argued that meritocratic societies offer only formal equality of opportunity rather than genuinely fair equality of opportunity, because treating individuals equally according the principles of procedural fairness neglects the impact of pre-existing structural inequalities on the capacity of individuals to demonstrate their true merit. Rawls defines 'fair equality of opportunity' or meritocratic equity of opportunity as requiring 'not merely that public offices and social positions be open in the formal sense, but that all should have a fair chance to attain them' (ibid: 43). By 'fair chance', Rawls argues that 'supposing that there is a distribution of native endowments, those who have the same level of talent and ability and the same willingness to use these gifts should have the same prospects of success regardless of their social class of origin, the class into which they are born and develop until the age of reason. In all parts of society there are to be roughly the same prospects of culture and achievement from those similarly motivated and endowed' (ibid 43-44).

Rawls argues that we cannot presume, as proponents of meritocratic equality of opportunity do, that unequal educational attainments simply reflect individual differences in innate ability cultivated by effort under equitable conditions. Rawls argues that:

native endowments of various kinds (say, native intelligence and natural ability) are not fixed natural assets with a constant capacity. They are merely potential and cannot come into fruition apart from social conditions; and when realized they can take but one or a few of many possible forms. Educated and trained abilities are always a selection, and a small selection at that, from a wide range of possibilities that might have been fulfilled. Among what affects their realisation are social attitudes of encouragement and support, and institutions concerned with their early discipline and use. Not only our conception of ourselves, and our aims and ambitions, but also our realised abilities and talents, reflect our personal history, opportunities and social position, and the influence of good and ill fortune. (ibid: 56-57)

As such, merit understood as the combination of natural ability and effort cannot be considered an achieved characteristic but instead represents an ascribed characteristic resulting from factors beyond the control of individuals including genetic luck and the socioeconomic circumstances of the family into which individuals happen to be born (Jacobs 2013). Correspondingly, as Rawls and others (e.g. Arrow, 1993) have argued, the equation of merit with deservingness is ultimately indefensible:

...we do not deserve (in the sense of moral desert) our place in the distribution of native endowments. This statement is meant as a moral truism. Who would deny it? Do people really think that they (morally) deserved to be born more gifted than others? Do they think that they (morally) deserved to be born a man rather than a woman, or vice versa? Do they think that they deserved to be born into a wealthier rather than a poorer family? No. (Rawls, 2001a: 74-75)

Importantly, Rawls was not calling for the abandonment of meritocracy altogether in favour of a random allocation of opportunities and resources regardless of merit, or for complete equality of outcome. Rather, Rawls argued in favour of what we term meritocratic equity of opportunity, requiring efforts to level the playing field in order to ensure genuinely fair (rather than merely formal) equality of opportunity. Accordingly, Rawls called for an emphasis on distributive fairness in place of procedural fairness, that is, for a conception and operationalisation of the principles of fairness with an eye to a more even distribution of outcomes.

Like Rawls' theory of justice as fairness, Sen's (2009) capabilities approach also emphasises that individuals must have more than the formal freedom to do or be what they aspire to; they must also have a real opportunity (the 'capability') to achieve these aspirations (to 
develop desired 'functionings'). While Rawls focuses on the need for a more equitable distribution of resources or 'primary goods', Sen's conception of fairness centres the extent to which people are able to make use of such resources to achieve desired ends. Sen, like Rawls, recognises that the real opportunities or capabilities of individuals depend on a range of personal, social, and environmental factors. As such, some individuals may require more resources or additional resources than others before they have the same level of opportunity to flourish.

In relation to higher education, a conception of fairness as meritocratic equity of opportunity necessitates a shift beyond access and admissions policies practices that adhere to the equal treatment rules of procedural fairness towards those designed to achieve a more proportionate allocation of university places at the group level. Like holistic (Liu, 2011) and affirmative action (Warikoo \& Allen, 2020) policies used elsewhere, the use of contextual data about the socioeconomic circumstances of individuals to inform university admissions decisions in England and the wider UK seeks a greater degree of distributive fairness in relation to higher education access and admissions, not by doing away with meritocratic selection criteria, but by placing constraints on their fair use (Jacobs 2013). This entails reaching judgements about the merit of applicants by considering their prior attainment in light of knowledge about the extent to which individuals have enjoyed equality of opportunity to have their abilities and efforts cultivated and rewarded (Clayton, 2012). This corresponds to a shift away from the 'democratic elitist' model of meritocratic equality of opportunity towards a 'social democratic' model which '[c] ognisant of unequal starting points arising from class privilege' judges fairness with reference to the equitable distribution of outcomes rather than equal procedures (Nahai, 2013).

Proponents of distributive rather than procedural fairness in relation to higher education access and admission have thus called for merit to be judged based on assessments of future potential rather than currently realised attainment as indicated by previous academic performance (Clayton, 2012). This might take the form of preferential admission to applicants from less advantaged backgrounds when selecting from among equally well qualified candidates, or requiring applicants from less advantaged backgrounds to meet lower academic entry requirements than their more advantaged peers in recognition of the more challenging socioeconomic circumstances in which those qualifications were achieved (Boliver et al., 2021). Proponents of distributive fairness in relation to higher education admissions have criticised the view that the purpose of universities is to provide fair access to exercise already-developed ability or that the purpose of a degree is to 'signal' productivity to prospective employers, arguing instead that universities have an important role to play in developing as-yet-unrealised potential (Boliver et al., 2018; Clayton, 2012).

\section{Evaluating the meritocratic equity of opportunity model of fair access}

While socioeconomic group differences in school attainment cannot be said to be fully objective indicators of merit, prior qualifications are an important predictor of the likelihood of subsequent success at degree level. Because of this, critics of the meritocratic equity of opportunity approach to university admissions argue that reducing academic entry requirements for socioeconomically disadvantaged applicants is likely to set them up to fail. 
However, A-level grades on entry to university have been found to be a more modest predictor of completing a degree than is often supposed, with a degree completion rate for students attending higher-tariff providers of $88 \%$ among those who entered with $\mathrm{AAB}$ at Alevel compared to an only slightly lower rate of $80 \%$ among those who entered with BCC (Boliver et al., 2021; see also Boliver et al., 2020). There is, however, a stronger association between grades on entry and rates of achieving a first or upper second class degree (sometimes referred to as a 'good degree'), with rates of $75 \%$ for students at higher-tariff providers who entered with $\mathrm{AAB}$ at A-level falling to $46 \%$ for those who entered with BCC. Similar patterns have been observed regarding the relationship between Scottish higher grades on entry and degree outcomes at Scottish universities, with evidence of a stronger relationship between grades on entry and final degree classification for degrees in science as compared to arts subjects (Boliver et al., 2020). While these patterns indicate that students entering universities with lower grades may be less well prepared for university study, on average, it also reflects the lack of support available to such students to enable them to bridge gaps in subject knowledge and academic skills (Boliver \& Powell, 2021).

That said, some studies have found that university students with certain markers of contextual disadvantage are more likely to be successful at degree level than their comparably qualified but more advantaged peers. Students educated in state schools have been found to perform better at degree level than privately schooled students with the same level of prior attainment at Bristol University (Hoare \& Johnston, 2011), at Oxford University (Ogg et al., 2009), at Russell Group universities (Boliver, Crawford, et al., 2017a), at UK medical schools (Kumwenda et al., 2017) and nationally (HEFCE, 2014), though anomalously not at Cambridge University (Partington, 2011). National data for the UK also shows that students whose prior attainment is higher than the average for their school perform better at degree level than comparably qualified students whose prior attainment is average or below average for their school (Crawford, 2014aHEFCE, 2014). This latter finding also holds for national data on medical students (Mwandigha et al., 2018) and for students attending the highly academically selective universities of St Andrews (Lasselle et al., 2014) and Cambridge (Partington, 2011).

The above findings relating to school type and academic performance relative to the school average have been used to support the case for a contextualised assessment of 'merit' which recognises that the prior attainments of comparatively disadvantaged students do not do full justice to their academic potential (CoWA, 2016; Schwartz, 2004). However, it is important to note that studies which measure comparative disadvantage at the area level or individual level rather than the school level tend to find that disadvantaged students are less likely to succeed at degree level than their comparably qualified but more advantaged peers. Poorer degree outcomes after controlling for pre-university attainment have been observed for students from economically deprived areas studying at Edinburgh University (Croxford et al., 2013) and nationally (Crawford, 2014a; HEFCE, 2014), as well as for students nationally from areas with low rates of participation in higher education (HEFCE, 2014) and from lower socioeconomic backgrounds (Crawford, 2014b; Crawford et al., 2016). These findings are unsurprising given that the negative impact of socioeconomic disadvantage on academic achievement is likely to persist after enrolment in higher education, raising the again issue of the need to support socioeconomically disadvantaged students to fulfil their potential once they are at university.

To date, only a small number of studies have explicitly explored the degree performances of socioeconomically disadvantaged students admitted via contextualised admissions policies in comparison with those admitted on the basis of standard entry requirements. One study, drawing on data for highly selective Sutton Trust 30 universities, found no evidence of lower 
rates of degree completion or of lower levels of degree performance overall at those institutions that were known to make contextual offers (Boliver, Gorard, \& Siddiqui, 2017b). A smaller scale study of Accountancy and Finance programmes at a Russell Group university found that those admitted with a two-grade reduction did just as well academically as their non-contextually admitted peers (Rowbottom, 2017). Other studies have examined the degree performance of students admitted to foundation year programmes designed to prepare socioeconomically disadvantaged students with grades lower than standard entry requirements for degree level study. An analysis of data from a Foundation Year programme at Oxford showed that students subsequently admitted to the university for undergraduate study with a three-grade reduction did just as well academically in their first year and second year exams as their non-contextually admitted peers (Begbie \& Fisher, 2019). Another study reported that of the 290 widening access students enrolled on Southampton University's preparatory year zero foundation programme for Medicine with BBC at A-level, 90\% successfully progressed onto year 1, 85\% of whom subsequently graduated with a medical degree (Curtis et al., 2014).

Owing to the relatively recent introduction of contextualised admissions policies in England, there are not yet any studies of the longer-term returns to higher education for those from socioeconomically disadvantaged backgrounds who were admitted with grades lower than standard entry requirements, or for those from more advantaged backgrounds with higher qualifications whose chances of a university place might have reduced as a result of contextualised admissions practices. However, one study of the impact of the University of Texas, Austin's policy of admitting students with performances that placed them in the top $10 \%$ within their school, found that the scheme increased enrolment rates, graduation rates, and subsequent earnings for those admitted to the university through the scheme, without corresponding negative effects for more advantaged individuals who might otherwise have gained places at the university (Black et al., 2020).

Overall, the existing statistical research shows that access and admissions to the UK's most academically selective universities is to some degree fair in the traditional meritocratic sense of being primarily attributable to corresponding differences in prior attainment. However, substantial socioeconomic inequalities in the chances of access remain even after indicators of 'merit' have been taken into account. Moreover, it is clear that pre-existing socioeconomic inequalities contribute to an attainment gap that widens over the course of the school career, in contradiction to the claim that all enjoy equality of opportunity to demonstrate their 'merit' regardless of socioeconomic circumstances. In addition, the evidence to date indicates that a contextualised approach to assessing prior attainment which takes individual socioeconomic circumstances into account can increase distributive fairness without necessarily jeopardising students' achievement at degree level, especially if students are supported to realise their potential once at university.

\section{Conclusions}

As this paper has shown, the traditional meritocratic equality of opportunity model of fair access to higher education can be considered fundamentally flawed. According to this model, university places should go to the most highly qualified candidates irrespective of social background in accordance with the principles of procedural fairness. However, the evidence indicates that this does not hold in practice, with 
prospective students from less advantaged backgrounds less likely than their comparably qualified but more advantaged peers to apply and be admitted to the most academically selective UK universities. More importantly, the traditional meritocratic equality of opportunity model rests on the untenable assumption that all have enjoyed prior equality of opportunity to demonstrate 'merit' through their performance in formal examinations. This is apparently not the case given that those with lower levels of economic, cultural, and social capital can be seen to fall steadily down the national distribution of attainment as their school careers progress.

As such, fair access cannot be conceptualised in terms of procedural fairness, interpreted to mean that university applicants should be treated the same when it comes to assessing 'merit'. Instead, there is a need to reconceptualise fair access in distributive fairness rather than procedural fairness terms. This involves the use of affirmative action measures which recognise and redress the impact of socioeconomic inequality on pre-university attainment, such as contextualised admissions practices involving lower academic entry requirements for disadvantaged applicants. An even simpler expedient might be to set minimum threshold qualifications for courses and admit all applicants who meet this threshold, with over-subscription resolved by lottery (Stone, 2013). The evidence to date suggests that such contextualised admissions practice can significantly widen access to the most academically selective universities without jeopardising student achievement, resulting in a greater degree of distributive fairness.

This discussion is framed by a highly competitive system that presumes differentiation on the grounds of academic selection to be necessary, both within and between universities as well as in admissions processes. Over time, higher education has come to be associated with academic competition, but the call to rethink how merit might be judged reminds us that higher education is not an immutable object. The oldest and most traditional universities demand the highest qualifications for entry, largely because they can do so, but justification for this practice is increasingly untenable. There is no empirical evidence to show highly selective universities offer improved educational outcomes. On the contrary, it may be that the achievements of students admitted to these universities stem from the material, cultural, and social capital that many enjoy by virtue of their privileged backgrounds, rather than the contributions made by the university itself. The principle function of academic selectivity in admissions, therefore, appears to be the maintenance of status differentiation between universities.

This raises the question as to why admissions need to be selective at all (Gorard et al., 2007; Zwick, 2017) with some suggesting that open enrolment could be the way forward (Sperlinger et al., 2018). It also raises the question whether fairness considerations should extend beyond access to higher education to the consequences of access as well, known as stakes fairness (Jacobs, 2010). Despite the lack of evidence on the impact of the most academically selective universities on educational outcomes, access to these universities can confer significant advantages in the labour market (Britton et al., 2020), making the competition for places high stakes. Young people have been found to be particularly attuned to stakes fairness, regarding as unjust the fact that performing poorly in exams or making "bad choices" in relation to upper secondary and higher education would have negative repercussions for 'the whole of life' (Mazzoli Smith et al., 2018). Importantly, the meritocratic equity of opportunity model advocated in this paper would not alter what is at stake in the competition for access, but would at least distribute more fairly the socioeconomic returns to attending a highly selective university. 
Funding This work was funded by grants from the Nuffield Foundation (EDO/42852) and the Economic and Social Research Council (ES/P002579/1).

Open Access This article is licensed under a Creative Commons Attribution 4.0 International License, which permits use, sharing, adaptation, distribution and reproduction in any medium or format, as long as you give appropriate credit to the original author(s) and the source, provide a link to the Creative Commons licence, and indicate if changes were made. The images or other third party material in this article are included in the article's Creative Commons licence, unless indicated otherwise in a credit line to the material. If material is not included in the article's Creative Commons licence and your intended use is not permitted by statutory regulation or exceeds the permitted use, you will need to obtain permission directly from the copyright holder. To view a copy of this licence, visit http://creativecommons.org/licenses/by/4.0/.

\section{References}

Adamecz-Völgyi, A., Henderson, M., \& Shure, N. (2020). Is 'first in family' a good indicator for widening university participation? Economics of Education Review, 78, 102038.

Anders, J. (2012). The link between household income, university applications and university attendance*. Fiscal Studies, 33(2), 185-210.

Anders, J., Green, F., Henderson, M., \& Henseke, G. (2020) Determinants of privatae school participation: All about the money?. British Educational Research Journal.

Arrow, K. J. (1993). Excellence and Equity in Higher Education. Education Economics, 1(1), 5-12.

Atherton, G., \& Nartey, A. (2019). Post-qualification application: A student centred model for higher education admissions in England, Northern Ireland and Wales. Universities and Colleges Admissions Service.

Begbie, J. and Fisher, E. (2019) Using individual-level contextual indicators to identify disadvantaged applicants: Evidence from the Foundation Year at Lady Margaret Hall, a college of Oxford University.

Bell, D. (1973). The coming of post-industrial society. Basic Books Inc..

Black, S.E., Denning, J.T and Rothstein, J. (2020) Winners and losers? The effect of gaining and losing access to selective colleges on education and labour market outcomes. Berkeley Centre for Studies in Higher Education Research \& Occasional Paper CSHE.2.2020. Berkeley University.

Boliver. (2013). How fair is access to more prestigious UK universities? British Journal of Sociology, 64(2), $344-364$.

Boliver. (2016). Exploring ethnic inequalities in admission to Russell Group universities. Sociology, 50(2), 247266.

Boliver, V., Gorard, S., Powell, M., \& Moreira, T. (2020). The use of access thresholds to widen participation at Scottish universities. Scottish Affairs, 29(1), 82-97.

Boliver, V. (2015). Lies, damned lies, and statistics on widening access to Russell Group universities. Radical Statistics, 113, 29-38.

Boliver, V., Crawford, C., Powell, M., \& Craige, W. (2017a). Admissions in context: The use of contextual information by leading universities. Project Report.

Boliver, V., \& Powell, M. (2021). Fair admission to universities in England: Improving policy and practice. Public Report for the Nuffield Foundation.

Boliver, V., Gorard, S., \& Siddiqui, N. (2021). Using contextual data to widen access to higher education. Perspectives: Policy and practice in Higher Education, 25(1), 7-13.

Boliver, V., Powell, M., \& Moreira, T. (2018). Organisational identity as a barrier to widening access in Scottish universities. Social Sciences, 7(9), 151.

Boliver, V., Gorard, S., \& Siddiqui, N. (2017b). How can we widen participation in higher education? The promise of contextualised admissions. In R. Deem \& H. Eggins (Eds.), In The University as a Critical Institution? (pp. 95-110). Sense Publishers.

Bourdieu, P. (1974). The school as a conservative force: Scholastic and cultural inequalities. In L. Eggleston (Ed.), In Contemporary Research in the Sociology of Education (pp. 32-46). Methuen.

Bourdieu, P. (1977). Cultural reproduction and social reproduction. In J. Karabel \& A. Halsey (Eds.), Power and Ideology in Education (pp. 487-511). Oxford University Press.

Britton, J., Dearden, L., van der Erve, L., \& Waltmann, B. (2020). The impact of undergraduate degrees on lifetime earnings. Department for Education and Institute for Fiscal Studies. 
Brown, P., Power, S., Tholen, G., \& Allouch, A. (2016). Credentials, talent and cultural capital: A comparative study of educational elites in England and France. British Journal of Sociology of Education, 37(2), 191211.

Campbell, S., Macmillan, L., Wyness, G., Bryson, A., Stokes, L., \& Wilkinson, D. (2019) Mismatch in higher education: prevalence, drivers and outcomes. Retrieved from www.nuffieldfoundation.org.

Cantwell, B., \& Marginson, S. (2018). Vertical stratification. In B. Cantwell, S. Marginson, \& A. Smolentseva (Eds.), High Participation Systems of Higher Education Oxford Scholarship Online.

Chowdry, H., Crawford, C., Dearden, L., Goodman, A., \& Vignoles, A. (2013). Widening participation in higher education: Analysis using linked administrative data. Journal of the Royal Statistical Society: Series A (Statistics in Society), 176(2), 431-457.

Cingano, F. (2014). Trends in income inequality and its impact on economic growth. In OECD Social, Employment and Migration Working Paper No. 163. OECD.

Clayton, M. (2012). On widening participation in higher education through positive discrimination. Journal of Philosophy of Education, 46(3), 414-431.

CoWA. (2016). A blueprint for fairness: The final report of the commission on widening access. Scottish Government.

Crawford (2014a) The link between secondary school characteristics and university participation and outcomes; HEFCE (2014) Differences in degree outcomes: key findings.

Crawford (2014b) Socioeconomic differences in university outcomes in the UK: drop-out, degree completion and degree class.

Crawford, C., Dearden, E., \& Micklewright, J. (2016). Family background and university success. Oxford University Press.

Crawford, C., Macmillan, L., \& Vignoles, A. (2017). When and why do initially high-achieving poor children fall behind? Oxford Review of Education, 43(1), 88-108.

Croxford, L., Docherty, G., Gaukroger, R. and Hood, K. (2013) Widening participation at the University of Edinburgh (3): entry, progression and degree outcomes by subject area.

Curtis, S., Blundell, C., Platz, C., \& Turner, L. (2014). Successfully widening access to medicine. Part 2: Curriculum design and student progression. Journal of the Royal Society of Medicine, 107(10), 393-397.

Dilnot, C., \& Boliver, V. (2018). Admission to medicine and law at Russell Group universities: the impact of Alevel subject choice. In P. J. Burke, A. Hayton, \& J. Stevenson (Eds.), In Evaluating Equity and Widening Participation in Higher Education (pp. 59-87). Trentham Books (UCL IOE Press).

Everett, N., \& Papageorgiou, J. (2011). Investigating the accuracy of predicted A level grades as part of 2009 UCAS admission process. Department for Business Innovation and Skills.

Goastellec, G. (2008). Globalization and implementation of an equity norm in higher education: Admission processes and funding framework under scrutiny. Peabody Journal of Education, 83(1), 71-85.

Gorard, S., \& Siddiqui, N. (2019). How trajectories of disadvantage help explain school attainment. SAGE Open, 9(1), 1-14.

Gorard, S., Adnett, N., May, H., Slack, K., Smith, E., \& Thomass, L. (2007). Overcoming the barriers to higher education. Trentham Books.

Gorard, S., Siddiqui, N., \& Boliver, V. (2017). An analysis of school-based contextual indicators for possible use in widening participation. Higher Education Studies, 7(2), 79.

Gorard, S., Boliver, V., Siddiqui, N., \& Banerjee, P. (2019). Which are the most suitable contextual indicators for use in widening participation to HE? Research Papers in Education, 34(1), 99-129.

Haj, C. M., Geanta, I. M., \& Orr, D. (2018). A typology of admission systems across Europe and their impact on the equity of access, progression and completion in higher education. In A. Curaj, L. Deca, \& R. Pricopie (Eds.), European Higher Education Area: The Impact of Past and Future Policies. Springer.

Harrison, N. (2019). Patterns of participation in higher education for care-experienced students in England: Why has there not been more progress? Studies in Higher Education. https://doi.org/10.1080/03075079.2019. 1582014.

HEFCE. (2014). Differences in degree outcomes: Key findings. HEFCE.

Hoare, A., \& Johnston, R. (2011). Widening participation through admissions policy - A British case study of school and university performance. Studies in Higher Education, 36(1), 21-41.

Holt-White, E., Montacute, R., \& Cullinane, C. (2020). PQA: Reforming university admissions. Sutton Trust.

Houston, M., Osborne, M., \& Rimmer, R. (2015). Private schooling and admission to medicine: A case study using matched samples and causal mediation analysis. BMC Medical Education, 15(1), 136.

Jacobs, L. A. (2010). Equality, adequacy, and stakes fairness: Retrieving the equal opportunities in education approach. Theory and Research in Education, 8(3), 249-268.

Kumwenda, B., Cleland, J. A., Walker, K., Lee, A. J., \& Greatrix, R. (2017). The relationship between school type and academic performance at medical school: A national, multi-cohort study. BMJ Open, 7, e016291. https://doi.org/10.1136/bmjopen-2017-016291. 
Lasselle, L., McDougall-Bagnall, J., \& Smith, I. (2014). School grades, school context and university degree performance: Evidence from an Elite Scottish Institution. Oxford Review of Education, 40(3), 293-314.

Littler, J. (2018). Against meritocracy: Culture, power and myths of mobility. Routledge.

Liu, A. (2011). Unraveling the myth of meritocracy within the context of US higher education. Higher Education, 62(4), 383-397.

Liu, Y. (2013). Meritocracy and the Gaokao: A survey study of higher education selection and socio-economic participation in East China. British Journal of Sociology of Education, 34(5-6), 868-887.

Liu, G. X. Y., \& Helwig, C. C. (2020) Autonomy, social inequality, and support in Chinese urban and rural adolescents' reasoning about the Chinese college entrance examination (Gaokao). Journal of Adolescent Research, 0743558420914082.

McNamee, S. J., \& Miller Jr., R. K. (2004). The meritocracy myth. Rowman \& Littlefield Publishers, Inc..

Marginson, S. (2018). Equity. In B. Cantwell, S. Marginson, \& A. Smolentseva (Eds.), High Participation Systems of Higher Education. Oxford Scholarship Online.

Mazzoli Smith, L., Todd, L., \& Laing, K. (2018). Students' views on fairness in education: the importance of relational justice and stakes fairness. Research Papers in Education, 33(3), 336-353.

Mwandigha, L. M., Tiffin, P. A., Paton, L. W., Kasim, A. S., \& Böhnke, J. R. (2018). What is the effect of secondary (high) schooling on subsequent medical school performance? A national, UK-based cohort study. BMJ Open, 8, e020291.

Nahai, R. N. (2013). Is meritocracy fair?A qualitative case study of admissions at the University of Oxford. Oxford Review of Education, 39(5), 681-701.

Noden, Shiner, \& Modood. (2014). University offer rates for candidates from different ethnic categories. Oxford Review of Education, 40(3), 349-369.

Norman, R. (1987). Free and equal (p. 68). Oxford University Press.

OECD. (2013). PISA 2012 Results: What makes schools successful? In Resources, Policies and Practices (IV ed.). PISA OECD Publishing.

Office for Students. (2018). A new approach to regulating access and participation in English higher education: Consultation Outcomes. Office for Students.

Office for Students (2019) Contextual admissions: Promoting fairness and rethinking merit. Insight Brief No. 3 , May 2019. Bristol: Office for Students.

Ogg, T., Zimdars, A., \& Heath, A. (2009). Schooling effects on degree performance: A comparison of the predictive validity of aptitude testing and secondary school grades at Oxford University. British Educational Research Journal, 35(5), 781-807.

Parsons, T. (1970). Equality and inequality in modern society, or social stratification revisited. In E. O. Lauman (Ed.), Social stratification: Research and theory for the 1970s. Indianapolis.

Partington, R.. (2011) Predictive effectiveness of metrics in admission to the University of Cambridge.https:// www.cao.cam.ac.uk/sites/www.cao.cam.ac.uk/files/ar_predictive_effectiveness_of_metrics_in_admission. pdf)

Rawls, J. (1971). A theory of justice. Harvard University Press.

Rawls, J. (2001). Justice as fairness: A restatement. Harvard University Press.

Reay, D. (2020). The perils and penalties of meritocracy: Sanctioning inequalities and legitimating prejudice. The Political Quarterly, 91(2), 405-412.

Rowbottom, N. (2017). Widening participation and contextual entry policy in accounting and finance. Accounting Education, 26(3), 242-264.

Schwartz, S. (2004). Fair admissions to higher education: Recommendations for good practice. HMSO.

Sen, A. (1979). Equality of what? The tanner lecture on human values, 22 May. Stanford University.

Sen, A. (2009) The idea of justice. Allen Lane.

Sperlinger, T., McLellan, J., \& Pettigrew, R. (2018). Who are universities for? Bristol University Press.

Stone, P. (2013). Access to higher education by the luck of the draw. Comparative Education Review, 57(3), 577-599.

Sullivan, A., Parsons, S., Wiggins, R., Heath, A., \& Green, F. (2014). Social origins, school type and higher education destinations. Oxford Review of Education, 40(6), 739-763.

Treiman, D. J. (1970). Industrialization and social stratification. In E. O. Lauman (Ed.), Social stratification: Research and theory for the 1970s. Bobbs-Merrill.

Warikoo, N., \& Allen, U. (2019). A solution to multiple problems: the origins of affirmative action in higher education around the world. Studies in Higher Education. https://doi.org/10.1080/03075079.2019.1612352.

Wikeley, F., Bullock, K., Muschamp, Y., \& Ridge, T. (2008). Educational relationships and their impact on poverty. International Journal of Inclusive Education, 13(4), 377-393.

Wyness. (2017). Rules of the game: Disadvantaged students and the university admissions process. Sutton Trust. Wyness, G. (2016). Predicted grades: Accuracy and impact. Universities and Colleges Union. 
Young, M. (1958). The rise of the meritocracy 1870-2033: An essay on education and society. Thames and Hudson.

Zimdars, A., Sullivan, A., \& Heath, A. (2009). Elite higher education admissions in the arts and sciences: Is cultural capital the key? Sociology, 43(4), 648-666.

Zwick, R. (2017) Who gets in? Strategies for fair and effective college admissions. Journal of Educational Measurement. Harvard University Press.

Publisher's note Springer Nature remains neutral with regard to jurisdictional claims in published maps and institutional affiliations.

\section{Affiliations}

\section{Vikki Boliver $^{1}$ - Pallavi Banerjee ${ }^{2} \cdot$ Stephen Gorard $^{3} \cdot$ Mandy Powell $^{4}$}

Pallavi Banerjee

p.banerjee@exeter.ac.uk

Stephen Gorard

s.a.c.gorard@durham.ac.uk

Mandy Powell

mandy.powell@durham.ac.uk

Department of Sociology, Durham University, Durham, UK

2 Graduate School of Education, University of Exeter, Exeter, UK

3 School of Education, Durham University, Durham, UK

4 Department of Sociology, Durham University, Durham, UK 